\title{
From leniency to lockout
}

\author{
By Henry J. DuBois \\ Media Resources Librarian \\ California State University, Long Beach
}

\section{Circulation policies at forty-three academic libraries.}

$\mathbf{I}_{1}$ which impact more directly upon library users than the formal or informal policies and procedures through which materials are loaned. Few areas also are likely to evoke as much controversy or to be quite so sensitive when changes are considered. Graduate and undergraduate students, faculty, alumni, and members of the community each have an interest in use of a library's collections and ideas about how that use should be regulated. All will profess their support for a fair, reasonable set of circulation guidelines, but reaching consensus on what is fair and reasonable can be difficult.

In the fall of 1985 at California State University, Long Beach, library director Jordan M. Scepanski appointed an ad hoc committee to review this institution's lending policies and procedures, which had seen few changes in over a decade. The Committee sought advice from as many of the library's constituencies as possible (through student and faculty consultative organizations such as senates and policy advisory committees), from the library staff, and from the library's community support group, Library Associates.

In addition to asking for comments and suggestions for change from library users, the Committee decided early in its deliberations that it needed to know what other similar libraries were doing, what policies had wide support and what guidelines for holds, fines, recalls, etc., had proven most effective. An online literature search gave some answers, but the Committee felt that it needed to know more. It designed a three-page survey questionnaire which focused on a broad range of circulation issues, and this instrument was mailed to forty-six academic libraries. The Committee sought this information from libraries of the other eighteen campuses in its own system, the California State University, from branches of the University of California, and from twenty-one "comparison" institutions nationwide, schools identified by the CSU as having characteristics similar to the campuses of its system. The survey group thus was far from homogeneous. It included large and small campuses, resident and commuter schools, some institutions with doctoral programs and libraries having large research collections, others with collections of relatively modest size and scope. It is surprising that, given these kinds of variations, the responses to the survey often revealed a good deal of consensus.

The Committee was gratified by the response to its poll. All but three of the libraries contacted, over $93 \%$, returned the questionnaire despite its rather formidable length. Not all schools responded to all questions, however, and some answers were not directly responsive to the questions. This will explain the variations in the numbers reported from the survey. What CSULB's study revealed about circulation practices at these institutions proved to be useful in formulating recommendations to improve its own policies and procedures. Other institutions considering reviews of this kind also may find the survey findings of help in identifying and/or building support for potential changes in existing lending rules.

\section{Lending and renewal}

Borrower categories and privileges have been established fairly predictably among the schools 
TABLE 1

Loan Periods

\begin{tabular}{lcr}
\hline \hline & $\begin{array}{c}\text { Institutions } \\
\text { responding }\end{array}$ & $\begin{array}{r}\text { Percent } \\
\text { responding }\end{array}$ \\
\hline Undergraduate & & $38 \%$ \\
4 week & 16 & $31 \%$ \\
3 week & 13 & $26 \%$ \\
2 week & 11 & $5 \%$ \\
semester/quarter & 2 & $28 \%$ \\
Graduate & & $30 \%$ \\
quarter/semester & 12 & $23 \%$ \\
4 week & 13 & $12 \%$ \\
3 week & 10 & $7 \%$ \\
2 week & 5 & $31 \%$ \\
other & 3 & $64 \%$ \\
Faculty & & $5 \%$ \\
annual/academic year & 13 & 27 \\
quarter/semester/6 month & 2 & \\
over l year & & \\
\hline
\end{tabular}

polled. Faculty tend to get the most privilegesquarterly, semestrally, annually, or even for indefinite loan periods; no fines; out-of-library use of periodicals, etc. In general, no distinction is made between part-time and full-time faculty for most privileges at these institutions. Alumni and community members tend to have the most restrictions placed on their use of the library, and for the most part they are awarded the same borrowing status as students. Graduate students enjoy a few more perquisites at the majority of the schools, such as longer loan periods and borrowing of bound periodicals.

Loan periods. The most frequently reported undergraduate loan periods for books were four weeks and three weeks; over two-thirds of the participating schools have one or the other. Libraries at eleven schools have a two-week loan, and two have a quarterly or semestral loan period. For faculty, quarterly/semestral or semi-annual loans prevail; twenty-seven schools have them, with thirteen schools establishing an annual or academic year checkout, and only two permitting indefinite loans.

Survey respondents at twelve libraries give their graduate students quarterly or semestral loans. In all cases but one, alumni are awarded lending priv- ileges identical to those of students. Part-time faculty are given the same generous loan privileges as regular faculty, with twenty-seven granting quarterly/semestral or six-month loans, and ten giving academic or calendar year loans. These data are shown in Table 1.

Unenrolled and unemployed patrons. One of the Committee's concerns was the practice of extending privileges beyond the period of enrollment or the employment contract. Students, for example, may seek borrowing privileges over the summer months or between the fall and spring terms. Parttime faculty may not hold a new employment contract between June and September. How do academic libraries deal with these situations?

Most do not extend privileges. Among the respondents $55 \%$, twenty-two schools, restrict lending to those currently enrolled or employed. Another $37 \%$ continue to honor library cards from the previous term, even though they have no real way to prevent abuse of privileges, but three of them $(8 \%)$ do so only for students; part-time faculty are cut off from lending when they are not under contract.

Return, renewal, recall. The study sought information about three chronic problem areas for libraries: returns, renewals, and recalls. Responding

TABLE 2

Renewals

\begin{tabular}{lcc}
\hline \hline & $\begin{array}{c}\text { Institutions } \\
\text { responding }\end{array}$ & $\begin{array}{c}\text { Percent } \\
\text { responding }\end{array}$ \\
\hline physical return required of students & 24 & $59 \%$ \\
physical return required of all borrowers & 19 & $46 \%$ \\
physical return not required & 17 & $41 \%$ \\
unlimited number of renewals & 34 & $85 \%$ \\
limited number of renewals & 6 & $15 \%$ \\
\hline
\end{tabular}


libraries at well over half of the schools require the physical return of library materials for renewal, although five (out of twenty-four) make faculty exempt from this requirement. At seventeen schools, $41 \%$ of those responding to this question, items can be renewed without being brought back to the library. A limit is imposed on the number of renewals at six of the polled schools, but two of these exempt faculty. A substantial majority, however, $85 \%$ of the respondents, have no renewal limit, except for off-campus borrowers at two institutions (see Table 2).

All responding to the poll indicated that they do attempt to recall material on which reserves or holds have been placed. Only three of the institutions participating in the poll $(7 \%)$ impose a limit on the number of library materials which a borrower may have at one time; forty respondents $(93 \%)$ have no limit, although a few of these limit high school or alumni patrons. Some schools said they would like to establish a limit, but have no practical way to do so under current circulation procedures.

\section{Enforcement mechanisms}

The questionnaire asked a number of questions focusing on the issue of enforcement. How is compliance with loan periods and recalls encouraged? Are fines imposed? If there is an online circulation system, does it have lockout capability, the capacity to deny privileges to borrowers with outstanding library obligations or who have failed to respond to a recall or overdue notice? If such a capacity exists, does the library make use of it? Who handles collection of bills - the library itself, or some other campus agency? Are faculty fined? Are they billed for lost or long overdue materials? The survey responses are summarized in Table 3.

Almost all the respondents said they do collect fines or late fees to encourage timely return of material; only $7 \%$ do not do so. Circulation lockout, a hold on student records, or a "processing fee" were suggested as alternatives to fines. Among the survey participants, $23 \%$ fine all categories of borrowers, but $67 \%$ exempt faculty from fines.

Bills for replacement. Bills for replacement often were reported to be the next level of sanction the responding schools initiate when materials remain unreturned. Libraries at twenty-five schools $(60 \%)$ either collect replacement charges from faculty or deny them access to some library or campus services until the bill has been settled, though three or four of these attempt to collect only "at retirement." Circulation officials at seventeen schools $(40 \%)$, lacking even this leverage, instead continue to entreat the offender to cooperate, and some try to enlist the aid of an academic dean or department head in this effort.

This relatively discreet, diplomatic approach and reluctance to invoke penalties does not, however, extend to students of the studied schools. Nearly all of these libraries bill for replacement, and thirty-seven said that fines or bills that remain unpaid will quickly trigger a hold on student grades, transcripts, registration, or other library/ campus services. Circulation departments at $63 \%$ of the responding schools collect their own fines and bills; $37 \%$ have this done through a business office or other campus agency.

Lockout. The survey showed that a large majority of the polled libraries (95\%) have and make use of the ability to lock out delinquent student borrowers, using an online circulation system to suspend their privileges. More than half $(57 \%)$ also use lockout for faculty. Graduate students and alumni also face lockout for outstanding library obligations at most of these schools; over two-thirds suspend privileges for graduates, and more than three-quarters do so for alumni. Lockout thresholds reported were quite low. Libraries at twelve schools $(32 \%)$ suspend privileges for one overdue item; eleven (30\%) use lockout when bills totaling $\$ 10$ or less have accumulated. These findings are illustrated in Table 4.

\section{Special materials}

In addition to book circulation the survey questionnaire asked about several other categories of materials. At California State University, Long Beach, non-print materials comprise a significant area of the collection, and the Committee wanted to know how CSU, UC, and comparison group li-

TABLE 3

Sanctions

\begin{tabular}{lcc}
\hline \hline & $\begin{array}{c}\text { Institutions } \\
\text { responding }\end{array}$ & $\begin{array}{c}\text { Percent } \\
\text { responding }\end{array}$ \\
\hline fines for students $\quad 39$ & $91 \%$ \\
$\quad$ faculty & 10 & $23 \%$ \\
no fines for faculty & 29 & $67 \%$ \\
no fines at all & 4 & $9 \%$ \\
bills, holds on records, services: & & \\
$\quad$ yes, students & 37 & $90 \%$ \\
no, students & 4 & $10 \%$ \\
yes, faculty & 25 & $60 \%$ \\
no, faculty & 17 & $40 \%$ \\
\hline
\end{tabular}


TABLE 4

Lockout

\begin{tabular}{lcr}
\hline \hline & $\begin{array}{c}\text { Institutions } \\
\text { responding }\end{array}$ & $\begin{array}{c}\text { Percent } \\
\text { responding }\end{array}$ \\
\hline have capability and use for & & $95 \%$ \\
undergraduates & 35 & $57 \%$ \\
faculty & 21 & $68 \%$ \\
graduates & 25 & $76 \%$ \\
alumni/courtesy & 28 & $14 \%$ \\
lockout threshold & & $32 \%$ \\
one recall & 5 & $8 \%$ \\
one overdue & 12 & $8 \%$ \\
$2-5$ overdues & 3 & $22 \%$ \\
bills under $\$ 5$ & 3 & $3 \%$ \\
bills $\$ 5-10$ & 8 & $16 \%$ \\
bills $\$ 11-25$ & 1 & 6 \\
bills over $\$ 25$ & 6 & \\
\hline
\end{tabular}

braries were dealing with these items. The survey revealed that for categories of media other than records or audiocassettes the majority of the respondents either do not collect the format at all, or, if they do have a collection, it is not loaned outside the building. Records and audiocassettes were cited as the materials most likely to be collected and loaned; films and microcomputer software were cited with the least frequency. In the relatively few institutions which do circulate media outside the library, faculty consistently enjoyed longer loan periods than students.

"Building Use Only." Pressed for space in their reference facility, librarians at CSULB Library have begun looking at other alternatives for housing reference materials. One option, putting them into the circulating book stacks, but making them "building use only," has been discussed. The ques- tionnaire asked if the surveyed libraries had established any building use collections and what sorts of materials had been designated for this treatment. Responses showed that thirty-three schools $(77 \%)$ have some kind of non-circulating materials other than reference or reserve. Bound periodicals were cited most often as items fitting this category, but several respondents said the designation was used for such things as reference materials relocated from the reference room, legal series, music monumenta and collected editions.

Periodicals. Librarians in the study group were fairly consistent in their lending policies for periodicals. A solid majority, $65 \%$ of those responding, do not lend unbound periodicals to undergraduate students at all. Only 2-hour loans are permitted for out-of-library use at four other institutions, and nine provide 1-3 day loans. The policies for gradu-

TABLE 5

Periodical Loans

\begin{tabular}{lcc}
\hline \hline & $\begin{array}{c}\text { Institutions } \\
\text { responding }\end{array}$ & $\begin{array}{c}\text { Percent } \\
\text { responding }\end{array}$ \\
\hline $\begin{array}{l}\text { Unbound Periodicals } \\
\text { undergraduate }\end{array}$ & & \\
$\quad$ no loan & 26 & $65 \%$ \\
$\quad$ one day or less & 9 & $23 \%$ \\
$\quad$ wo days or more & 5 & $12 \%$ \\
faculty & & $38 \%$ \\
$\quad$ no loan & 15 & $36 \%$ \\
$\quad$ one day or less & 14 & $26 \%$ \\
$\quad$ two days or more & 10 & \\
Bound Periodicals & & $67 \%$ \\
undergraduate & & $23 \%$ \\
$\quad$ no loan & 26 & $10 \%$ \\
one day or less & 9 & \\
$\quad$ two days or more & 4 & $29 \%$ \\
faculty & & $31 \%$ \\
$\quad$ no loan & 12 & $40 \%$ \\
$\quad$ one day or less & 13 & \\
two days or more & 17 & \\
\hline
\end{tabular}


ate students are identical at all but two schools, where they are slightly more generous. For alumni borrowers periodical loans are slightly more restrictive at three schools, identical to student loans at others. Faculty checkout of unbound periodicals is not permitted by over a third of the participating libraries. Another third of the remaining respondents provide a one-day loan or less to faculty, and the others allow periods from 3 days to "no limit."

Bound periodicals are not loaned at all to undergraduates by over two-thirds of the polled institutions. The next largest group $(23 \%)$ have established loan periods of up to one day. Special privileges are granted to graduate students at five institutions, allowing them in most cases to borrow bound periodicals overnight or one day, and one permits loans of a full week to those writing a thesis.

Faculty at twelve of the responding schools are given no borrowing privileges for bound periodicals. A slightly larger number, $31 \%$ of the surveyed libraries, grant loans of one day or less, with most others giving one week or less. There were isolated examples also of semestral and unlimited faculty loans for bound periodicals; but these are hardly typical and they tend to be peculiar to schools hav-

\section{BI abstracts wanted}

The 15th Library Orientation and Exchange (LOEX) conference, "Defining and Applying Teaching Strategies for Library Instruction," will be held May 6, 7, and 8, 1987, at the Ohio State University, Columbus, Ohio. Abstracts for half-hour instructive sessions are being sought. Accepted abstracts will be published in the conference proceedings.

Instructive sessions should deal with specific teaching methods and/or strategies (such as effective use of microcomputers, specific audiovisual equipment, etc.) or specific strategies on library instruction for specific user groups (such as international students, adult students, etc.). Each session will be repeated at least twice during the conference.

Participants in previous LOEX conferences have expressed interest in the following topics, but abstracts concerning other topics are equally welcome: media production techniques; CAI programs for library instruction; brochure and handout design; BI for the disabled user; BI for the foreign student; creative uses of $\mathrm{A}-\mathrm{V}$; optical disk in $\mathrm{BI}$; alternatives to the lecture.

Submit a one-page abstract with proposed title, audiovisual requirements, your name, address, and phone number by February 1, 1987, to: Mary-Beth Bunge, Chair, LOEX 1987 Program Committee, Office of Library User Education, Ohio State University Libraries, 1858 Neil Avenue Mall, Columbus, OH 43210. ing relatively small libraries and enrollments. Periodical lending is summarized in Table 5.

The survey concluded with an open-ended question: "What are the main problems or concerns your library confronts in the area of lending policies?" By far the largest number of responses (twenty-four) cited faculty non-compliance with library lending policies as a significant challenge. Another ten responded that recalls are difficult or impossible to enforce; this also is an area often related to faculty borrowing. Problems with external borrowers were cited by nine of those polled, the inability to enforce lending rules among those not affiliated with the campus. Another seven schools said that fine or billing disputes are a problem area, that students claimed to have returned material which cannot be located, feel that penalties are too harsh, or that the library has failed to advise them adquately about infractions or penalties.

\section{Conclusion}

The survey revealed greater consistency than the Committee expected to see among the institutions polled, representing as they did wide variations in size, geographic location, and campus/clientele characteristics. For CSULB Library, and perhaps for the survey participants, it was useful to know that lending rules in force already or being recommended for adoption did not represent an aberration from the norm for other academic libraries in California and nationwide.

The most helpful and useful data for the study committee were those related to lockout. California State University, Long Beach Library has had an automated circulation system and lockout capability for years. Thresholds, however, have always been set at very high levels, with the effect of virtually never letting the system fulfill its potential to promote borrower compliance with lending regulations. Armed with the survey findings the Committee felt more confident about proposing a new set of thresholds, knowing there were ample precedents for success in their use by other libraries.

Once the survey findings had been tabulated the Committee recommended to director Jordan Scepanski a series of sixteen changes in existing circulation policies and procedures. This list was grouped into items which really were internal matters, having little or no impact on student and faculty borrowers, and those requiring faculty and/or student consultation. The consultative process, during which the recommendations were presented and justified to the campus community, took an additional six months to complete. Development of the Committee's recommendations involved three sets of input: from survey findings, invited faculty/student recommendations, and the Committee's own perspectives. Because the final report and recommendations synthesized these components the Committee could look with considerable optimism for its ultimate acceptance by all of the Library's constituencies. 


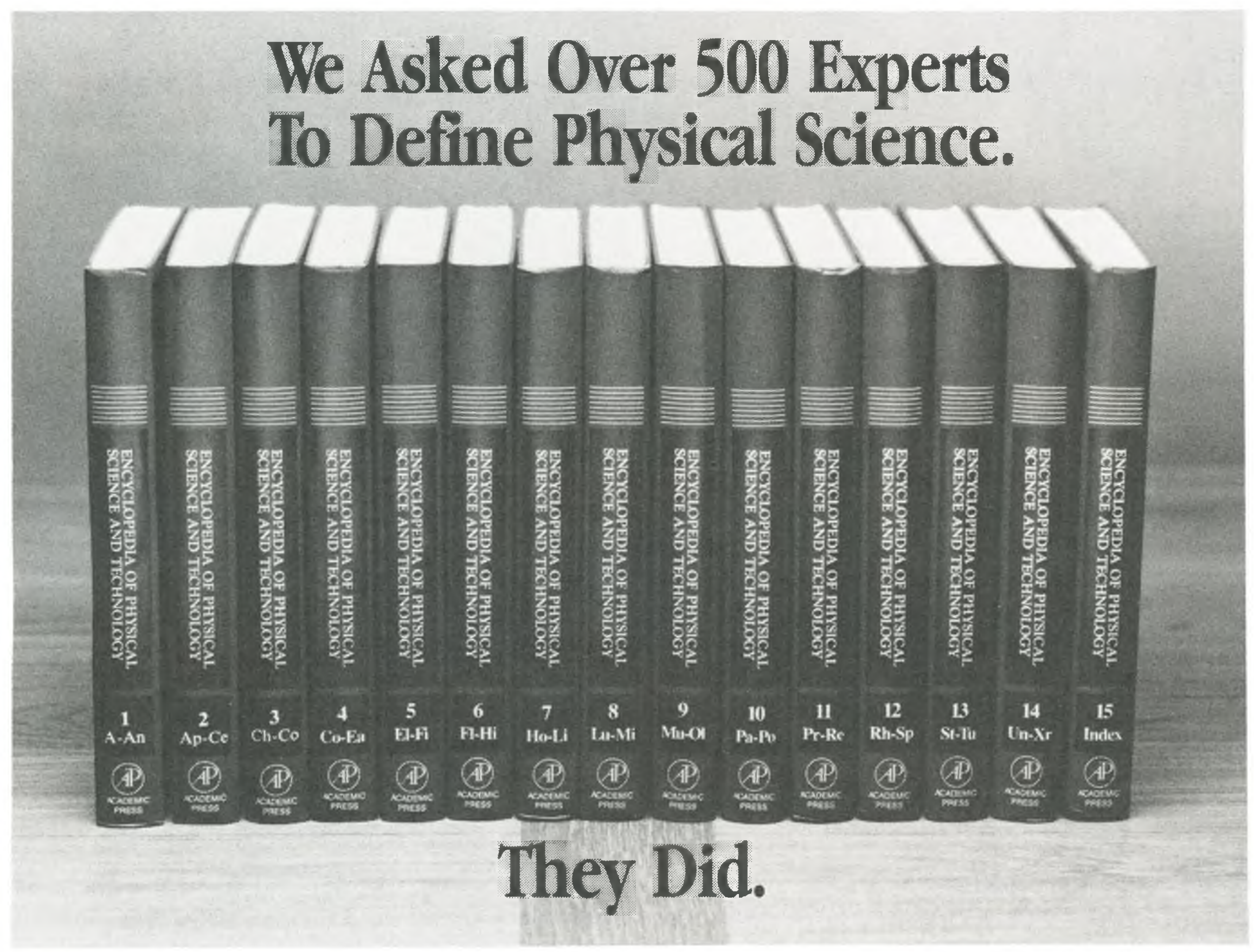

\section{Encyclopedia of Physical Science and Technology}

\section{Robert A. Meyers, Editor-in-Chief}

The Encyclopedia of Physical Science and

Technology is the contemporary reference for today's high technology. It is a unique source, and the first to encompass all aspects of the physical sciences. A complete technical library, the Encyclopedia is:

\section{..... DETAILED}

- 15 volumes ... including a separate index volume - Over 500 original articles each approximately 20 pages long $\cdot 6,000$ illustrations $-2,000$ tables - 11,000 double column pages $\cdot$ Extensive cross referencing.

\section{COMPREHENSIVE}

The Encyclopedia covers these major subjects:

- Aeronautics $\bullet$ Astronomy \& Astrophysics • Atmospheric Sciences \& Aeronomy $\bullet$ Chemistry $\bullet$ Communications - Computers \& Controls $\bullet$ Earth Sciences \& Oceanography $\bullet$ Electronics \& Electrical Engineering • Materials Science \& Engineering - Mathematics $•$ Mechanical, Industrial, and Civil Engineering $\bullet$ Military Sciences $\bullet$ Navigation, Military Communications $\cdot$ Nuclear Technology

- Ordnance $\bullet$ Physics $\bullet$ Power Systems, Non Nuclear
\& Non Propulsive $\cdot$ Propulsion \& Fuels

- Space Technology.

\section{..... ORGANIZED}

Articles are arranged alphabetically and include: table of contents, glossary of unusual terms, concise definition of subject, in depth presentations, extensive cross references, illustrations, tables and a bibliography.

The Encyclopedia of Physical Science and Technology is the required reference for today's scientist, engineer and student.

For more information and details of a special $\$ 400$ prepublication saving contact Linda Frank at 305-345-2734, or write for a complete prospectus to:

\section{(AP)Academic Press}

Harcourt Brace Jovanovich, Publishers Attn: Sales Department

Orlando, FL 32887 80126-DT/IY 